
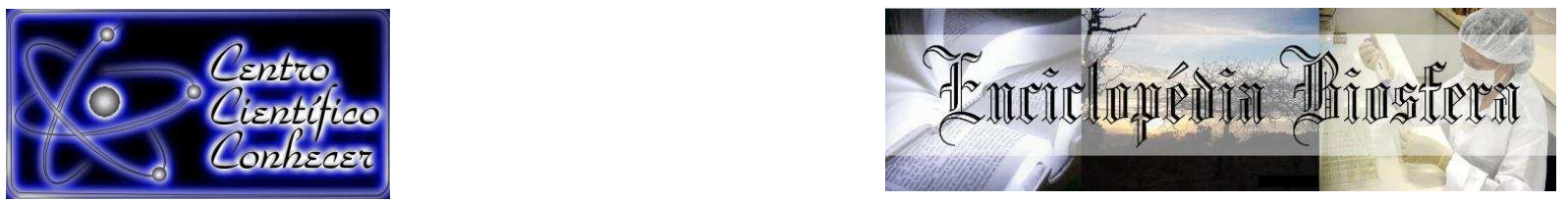

\title{
ARRANJAMENTOS ESPACIAIS E DENSIDADES DE PLANTIO NA PRODUÇÃO DE REPOLHO
}

Renata Castoldi ${ }^{1}$, Eduardo Luís Lopes Curi ${ }^{2}$, Rafaelle Fazzi Gomes ${ }^{3}$, Hamilton César de Oliveira Charlo ${ }^{4}$, Leila Trevisan Braz ${ }^{5}$

1 Professora Doutora da Universidade Estadual de Minas Gerais, UEMG, PassosMG. rcastoldi@gmail.com

2 Engenheiro Agrônomo da Faculdade de Ciências Agrarias e Veterinárias, UNESP-FCAV, Jaboticabal-SP

3 Professora Assistente da Universidade Federal Rural da Amazônia, Campus Capanema-PA

${ }^{4}$ Professor Doutor do Instituto Federal de Educação Ciência e Tecnologia Triângulo Mineiro - IF Triângulo, Uberaba-MG

5 Professora Doutora do Departamento de Produção Vegetal (Horticultura) da

Faculdade de Ciências e Agrárias e Veterinárias, UNESP-FCAV, Jaboticabal-SP

Recebido em: 08/09/2015 - Aprovado em: 14/11/2015 - Publicado em: 01/12/2015 DOI: http://dx.doi.org/10.18677/Enciclopedia_Biosfera_2015_246

\section{RESUMO}

A alteração no espaçamento entre plantas e entre linhas (densidade populacional) e arranjamentos espaciais, promovem alterações expressivas nas plantas. A melhor compreensão destes fatores poderá proporcionar melhor manejo da cultura, melhor produtividade e melhor qualidade do repolho. Com base nisto, objetivou-se com este trabalho avaliar diferentes espaçamentos e arranjamentos espaciais, na cultura do repolho. O delineamento experimental utilizado foi blocos casualizados, com 18 tratamentos e três repetições, em esquema fatorial $3 \times 3 \times 2$. Cada parcela foi constituída por 28 plantas, sendo as dez plantas centrais a parcela útil, utilizadas para a avaliação. Foram avaliados três espaçamentos entrelinhas $(0,4 \mathrm{~m} ; 0,6 \mathrm{~m} ; 0,8 \mathrm{~m})$, três espaçamentos entre plantas $(0,3 \mathrm{~m} ; 0,5 \mathrm{~m} ; 0,7 \mathrm{~m})$ e dois arranjamentos espaciais (triangular e quadrangular), sendo os tratamentos compostos das 18 combinações possíveis entre os espaçamentos entrelinhas, espaçamentos entre plantas e arranjamentos espaciais. As avaliações realizadas mensuraram as seguintes características: altura da cabeça, diâmetro da cabeça, índice de formato da cabeça, compacidade, massa fresca e produtividade total estimada. Considerando a atual preferência brasileira e a busca de maior produtividade pelo produtor, o espaçamento de 0,4 x 0,5 m (entrelinhas e entre plantas, respectivamente) é o mais indicado, por promover cabeças com características comercializáveis, mantendo alta produtividade. Quanto ao arranjamento espacial (triangular ou quadrangular), não houve interferência para as características avaliadas.

PALAVRAS-CHAVE: Brassica oleraceae var. capitata, disposição espacial, espaçamentos, 


\title{
SPATIAL ARRANGEMENT AND SPATIAL DENSITY ON CABBAGE YIELD
}

\begin{abstract}
The change in spacing between plants and between rows (population density) and spatial Cupboards, promote significant changes in plants. A better understanding of these factors might provide better crop management, improved productivity and better quality cabbage. On that basis, the aim of this work was to evaluate different spacing and spatial Cupboards in cabbage culture. The experimental design was randomized blocks with 18 treatments and 3 replications in a factorial $3 \times 3 \times 2$. Each plot consisted of 28 plants, and the ten central plants useful portion, used for evaluation. We evaluated three row spacings $(0.4 \mathrm{~m}, 0.6 \mathrm{~m}, 0.8 \mathrm{~m})$, three spacing between plants $(0.3 \mathrm{~m}, 0.5 \mathrm{~m}$, $0.7 \mathrm{~m}$ ) and two space Cupboards (triangular and rectangular) and the treatments composed of the 18 possible combinations between the lines spacing, spacing between spatial plans and Cupboards. The evaluations conducted measured the following characteristics: head height, head diameter, head shape index, compactness, fresh and estimated total productivity. Considering the current Brazilian preference and the pursuit of higher productivity by the producer, the spacing of $0.4 \times 0.5 \mathrm{~m}$ (rows and between plants, respectively) is the most suitable for promoting heads with marketable characteristics while maintaining high productivity. As for the space arranjamento (triangular or square), there was no interference to the characteristics evaluated
\end{abstract}

KEYWORDS: Brassica oleraceae var. capitata, space disposition, spacing

\section{INTRODUÇÃO}

Entre as várias hortaliças ofertadas aos consumidores brasileiros, o repolho é a hortaliça de maior relevância econômica entre as variedades botânicas da espécie Brassica oleracea (SILVA et al., 2011). Inúmeras pesquisas têm sido realizadas, dada sua importância na alimentação humana, seja pela quantidade consumida, pelo alto valor nutricional ou pela elevada produtividade (FERREIRA et al., 2002).

Nos primeiros sete meses de 2014, o CEAGESP comercializou 31.951 toneladas de repolho (AGRIANUAL, 2015), apresentando fortes tendências de crescimento, em função do consumo interno e da mudança de hábito alimentar do brasileiro, demonstrando a importância desta hortaliça para a economia.

Segundo SILVA et al. (2011) dentre os vários fatores de produção a serem estudados para as novas cultivares disponíveis no mercado, tem-se o espaçamento ou densidade de plantio. De modo geral, estudos sobre espaçamentos visam maximizar a população de plantas por unidade de área, pois, inúmeras são as vantagens proporcionadas pelo adensamento, tais como: redução da infestação do cultivo por plantas daninhas; redução do tamanho do produto a ser comercializado e do ciclo; aumento da cobertura e proteção do solo; maior eficiência no aproveitamento de insumos aplicados (fertilizantes e agrotóxicos) e recursos disponíveis (água, luz e solo) e aumento de produtividade.

$\mathrm{Na}$ cultura do repolho, os espaçamentos mais recomendados e utilizados estão entre 0,7 a 0,8 m entrelinhas e 0,3 a 0,5 m entre plantas, em fileiras simples. Porém, se o objetivo for produzir cabeças menores, atualmente mais valorizadas, recomenda-se utilizar fileiras duplas, no espaçamento de 0,8 $\times 0,3 \times 0,3 \mathrm{~m}$, no arranjamento triangular (FILGUEIRA, 2012). 
De acordo com PÔRTO et al. (2012), a variação no espaçamento entrelinhas ou entre plantas pode modificar a competição entre indivíduos de uma cultura, com repercussão no crescimento e desenvolvimento das plantas, alterando a rentabilidade do cultivo, tendo que as principais variáveis que influenciam na escolha da densidade mais adequada são: genótipo da planta, condições edafoclimáticas durante o desenvolvimento, fertilidade do solo, temperatura do ar, pluviometria, irrigação e adubação. O adensamento da cultura do repolho resulta na produção de cabeças mais compactas (SILVA JUNIOR, 1987), atendendo melhor as exigências do mercado consumidor, que são cabeças pesando entre 1,0 a 1,5 kg (LÉDO et al., 2000).

AQUINO et al. (2005) avaliaram o efeito de doses de nitrogênio e espaçamentos sobre as características qualitativas e produtivas do repolho, e observaram que a diminuição do espaçamento resulta na redução da massa fresca, do volume, dos diâmetros transversal e longitudinal além de maior perda de massa pós-colheita.

Além do espaçamento e, consequentemente, da densidade de plantio, a manipulação adequada do arranjamento estrutural das plantas na lavoura, pode apresentar, entre outras vantagens, maior eficiência na interceptação da radiação solar (THOMÉ, 1985), uso mais efetivo da umidade e dos nutrientes do solo ou das adubações e menor competição radicular (WOOLEY \& DAVIS, 1991), além de representar um método importante e de baixo custo no controle de invasoras e de diversas enfermidades (KRANZ, 1989).

A alteração no espaçamento entre plantas e entre linhas (densidade populacional) e arranjamentos espaciais, promovem alterações expressivas nas plantas. A melhor compreensão destes fatores poderá proporcionar melhor manejo da cultura, melhor produtividade e melhor qualidade do repolho. Com base no exposto, o objetivo deste experimento foi avaliar o desempenho do híbrido de repolho 'Astrus Plus' em diferentes espaçamentos entrelinhas, entre plantas e arranjamentos espaciais.

\section{MATERIAL E MÉTODOS}

O experimento foi desenvolvido em campo, em área experimental do Setor de Olericultura e Plantas Aromático-Medicinais, pertencente ao Departamento de Produção Vegetal, da Faculdade de Ciências Agrárias e Veterinárias (UNESP-FCAV), Campus de Jaboticabal. A altitude local é de $614 \mathrm{~m}$, com latitude Sul de 21ํ 14' 05" e longitude Oeste de 48ㅜ 17' 09". O solo da área experimental foi classificado como Latossolo eutroférrico (EMBRAPA, 2014). A área ocupada pelo trabalho foi de $63 \mathrm{~m}$ de comprimento por 12 metros de largura, totalizando $756 \mathrm{~m}^{2}$.

O delineamento experimental utilizado foi de blocos casualizados, em esquema fatorial $3 \times 3 \times 2$, totalizando, portanto, 18 tratamentos com três repetições. Cada parcela foi constituída de quatro linhas com sete plantas cada, sendo a parcela útil as dez plantas centrais. Os tratamentos consistiram da combinação de três espaçamentos entrelinhas $(0,4 \mathrm{~m} ; 0,6 \mathrm{~m}$ e $0,8 \mathrm{~m})$, três espaçamentos entre plantas $(0,3 \mathrm{~m} ; 0,5 \mathrm{~m}$ e 0,7 $\mathrm{m}$ ) e dois arranjamentos espaciais (triangular e quadrangular).

O híbrido utilizado foi "Astrus Plus", caracterizado por possuir ciclo de 95-100 dias; plantas vigorosas, de tamanho médio; folhas de coloração verde escura com boa cerosidade; cabeças médias a grandes, com formato levemente achatado, de 1,8-2,5 kg; coração pequeno e excelente compacidade (SEMINIS, 2011). 
A semeadura foi realizada no início de outubro, utilizando bandejas de poliestireno expandido com 128 células, preenchidas com substrato Plantmax Hortaliças $\mathrm{HT}^{\circledR}$. As bandejas foram acondicionadas em ambiente protegido do tipo arco, com dimensões de $15 \mathrm{~m}$ de comprimento, $7 \mathrm{~m}$ de largura, $3 \mathrm{~m}$ de pé direito e com cobertura de polietileno de baixa densidade (PEBD), de 150 micras de espessura.

O transplante para o campo foi realizado 50 dias após a semeadura, ou seja no fim de novembro, em área anteriormente preparada, conforme sistema convencional (aração e gradagem), calcareado para elevar a saturação por bases a $80 \%$, e adubado cinco dias antes do transplante, conforme a análise química do solo e as recomendações para a cultura, de acordo com TRANI et al. (1997).

A adubação de plantio constou de $60 \mathrm{~kg} \mathrm{ha}^{-1}$ de $\mathrm{N}, 200 \mathrm{~kg} \mathrm{ha}^{-1}$ de $\mathrm{P}_{2} \mathrm{O}_{5}$, e $180 \mathrm{~kg}$ ha $^{-1}$ de $\mathrm{K}_{2} \mathrm{O}$, tendo como fontes de nutrientes, sulfato de amônio, superfosfato simples e cloreto de potássio, respectivamente. Foram efetuadas quatro adubações de cobertura, sendo a primeira aos 15 dias após o transplante, e as demais em intervalos de 15 dias, totalizando $150 \mathrm{~kg} \mathrm{ha}^{-1}$ de $\mathrm{N}$ e $75 \mathrm{~kg} \mathrm{ha}^{-1}$ de $\mathrm{K}_{2} \mathrm{O}$, utilizando-se como fonte uréia e cloreto de potássio, respectivamente. A irrigação utilizada foi por aspersão, com turno diário para manter o solo sempre úmido e adequado para melhor desenvolvimento da cultura.

O controle fitossanitário foi realizado sempre quando necessário, sendo realizada inspeção diária para verificar a necessidade de controle. A cultura foi toda conduzida no limpo, por meio de capinas manuais. A colheita foi realizada quando as cabeças apresentavam-se compactas e completamente desenvolvidas, sendo realizadas as seguintes avaliações: altura da cabeça $(\mathrm{mm})$ diâmetro da cabeça $(\mathrm{mm})$; índice de formato da cabeça (obtido pela razão entre a altura e diâmetro da cabeça); massa fresca $(\mathrm{kg})$; compacidade (obtida através da atribuição de notas de 1 a 3 , sendo 1 pouco compacto, 2 - medianamente compacto e 3 - muito compacto, utilizando a média de oito cabeças) e produtividade total estimada ( $\left.\mathrm{t} \mathrm{ha}{ }^{-1}\right)$.

Todas as características avaliadas foram submetidas à análise de variância, e quando $\mathrm{o}$ valor de $\mathrm{F}$ calculado foi significativo, realizaram-se comparações entre médias pelo teste de Tukey, ao nível de $5 \%$ de probabilidade, através do Programa AgroEstat (BARBOSA \& MALDONADO, 2011).

Para melhor interpretação do efeito conjunto dos fatores espaçamentos entrelinhas e espaçamentos entre plantas na análise de variância, realizou-se o estudo de superfície de resposta polinomial quadrática. Quando esta foi significativa (Teste F, $\mathrm{P}<0,05)$, este modelo foi utilizado para o estudo da interação dos fatores espaçamentos entrelinhas e espaçamentos entre plantas. O modelo utilizado para estudo da superfície de resposta foi: $z=b_{0}+b_{1} x+b_{2} y+b_{3} x^{2}+b_{4} x y+b_{5} y^{2}$, onde: $x$ = espaçamento entrelinhas; $y=$ espaçamento entre plantas; $z=$ variável dependente $e$ $b_{0}, b_{1}, b_{2}, b_{3}, b_{4}, e b_{5}=$ parâmetros do modelo.

\section{RESULTADOS E DISCUSSÃO}

$\mathrm{Na}$ Tabela 1, são apresentadas as médias da altura da cabeça $(\mathrm{mm})$, diâmetro da cabeça $(\mathrm{mm})$, índice de formato da cabeça, compacidade, massa fresca $(\mathrm{kg}) \mathrm{e}$ produtividade total estimada $\left(\mathrm{t} \mathrm{ha}^{-1}\right)$, obtidas no cultivo do híbrido de repolho 'Astrus Plus', conduzido em diferentes espaçamentos entrelinhas, entre plantas e 
arranjamentos espaciais. Houve interação significativa entre todos os fatores (interação tripla) apenas para as características compacidade e produtividade total estimada. Para as demais características os dados serão discutidos separadamente.

Houve ajuste significativo da superfície de resposta em função da interação espaçamento entrelinhas e entre plantas apenas para a característica diâmetro da cabeça no arranjamento espacial triangular e para massa fresca no arranjamento espacial triangular (Tabela 2).

TABELA 1 Médias das características altura da cabeça (AC), diâmetro da cabeça (DC), índice de formato da cabeça (IFC), compacidade (C), massa fresca (MF) e produtividade total estimada (PTE), obtidas pelo híbrido de repolho 'Astrus Plus' em diferentes densidades de plantio e arranjamentos espaciais.

\begin{tabular}{|c|c|c|c|c|c|c|}
\hline Tratamentos & $\mathrm{AC}(\mathrm{mm})$ & $\mathrm{DC}(\mathrm{mm})$ & IFC & $\mathrm{C}$ & $\mathrm{MF}(\mathrm{kg})$ & PTE $\left(\mathrm{t} \mathrm{ha}^{-1}\right)$ \\
\hline \multicolumn{7}{|c|}{ Espaçamentos entrelinhas (EEL) } \\
\hline $0,4 \mathrm{~m}$ & $122,04 \mathrm{~b}$ & $164,90 \mathrm{~b}$ & $0,74 \mathrm{a}$ & $2,55 \mathrm{a}$ & $1,16 \mathrm{~b}$ & $58,75 \mathrm{a}$ \\
\hline $0,6 \mathrm{~m}$ & $128,74 \mathrm{a}$ & $175,81 \mathrm{ab}$ & $0,74 \mathrm{a}$ & $2,62 \mathrm{a}$ & $1,41 \mathrm{a}$ & $48,70 \mathrm{~b}$ \\
\hline $0,8 \mathrm{~m}$ & $133,33 \mathrm{a}$ & $181,40 \mathrm{a}$ & $0,73 \mathrm{a}$ & $2,70 \mathrm{a}$ & $1,62 \mathrm{a}$ & $43,54 \mathrm{~b}$ \\
\hline Teste F & $10,32^{* *}$ & $6,03^{\star *}$ & $0,15^{\mathrm{ns}}$ & $1,65^{\mathrm{ns}}$ & $13,79^{* *}$ & $13,69^{* *}$ \\
\hline DMS (5\%) & 6,13 & 11,84 & 0,044 & 0,195 & 0,211 & 7,25 \\
\hline \multicolumn{7}{|c|}{ Espaçamentos entre plantas (EEP) } \\
\hline $0,3 \mathrm{~m}$ & $119,50 \mathrm{c}$ & $161,75 \mathrm{~b}$ & $0,75 \mathrm{a}$ & $2,36 \mathrm{~b}$ & $1,01 \mathrm{~b}$ & $56,47 a$ \\
\hline $0,5 \mathrm{~m}$ & $128,17 b$ & $177,81 \mathrm{a}$ & $0,74 \mathrm{a}$ & $2,69 a$ & $1,49 a$ & $51,83 \mathrm{a}$ \\
\hline $0,7 \mathrm{~m}$ & $136,45 a$ & $182,55 \mathrm{a}$ & $0,72 \mathrm{a}$ & $2,82 a$ & $1,69 a$ & $42,69 \mathrm{~b}$ \\
\hline Teste $\mathrm{F}$ & $23,00^{* *}$ & 10,19 ** & $1,39^{\mathrm{ns}}$ & $18,07^{* *}$ & $32,04^{* *}$ & $11,26^{\star *}$ \\
\hline DMS (5\%) & 6,13 & 11,84 & 0,04 & 0,19 & 0,22 & 7,25 \\
\hline \multicolumn{7}{|c|}{ Arranjamentos espaciais (AE) } \\
\hline Triangular & $127,15 \mathrm{a}$ & $174,59 \mathrm{a}$ & $0,73 \mathrm{a}$ & $2,58 \mathrm{a}$ & $1,35 \mathrm{a}$ & $48,81 \mathrm{a}$ \\
\hline Quadrangular & $128,93 \mathrm{a}$ & $173,48 \mathrm{a}$ & $0,75 \mathrm{a}$ & $2,67 a$ & $1,45 \mathrm{a}$ & $51,86 \mathrm{a}$ \\
\hline Teste $\mathrm{F}$ & $0,76^{\mathrm{ns}}$ & $0,79^{\mathrm{ns}}$ & $1,19^{\mathrm{ns}}$ & $2,01^{\text {ns }}$ & $1,91^{\mathrm{ns}}$ & $1,59^{\mathrm{ns}}$ \\
\hline DMS (5\%) & 4,15 & 8,02 & 0,03 & 0,13 & 0,15 & 4,91 \\
\hline \multicolumn{7}{|c|}{ Interações } \\
\hline EEL $x$ EEP & $0,25^{\mathrm{ns}}$ & $0,45^{\mathrm{ns}}$ & $0,16^{\mathrm{ns}}$ & $0,99^{\mathrm{ns}}$ & $0,56^{\mathrm{ns}}$ & $1,71^{\mathrm{ns}}$ \\
\hline$E E L \times A E$ & $0,23^{\mathrm{ns}}$ & $0,85^{\mathrm{ns}}$ & $1,17^{\mathrm{ns}}$ & $2,96^{\mathrm{ns}}$ & $0,44^{\mathrm{ns}}$ & $0,08^{\mathrm{ns}}$ \\
\hline $\mathrm{EEP} \times \mathrm{AE}$ & $0,31^{\mathrm{ns}}$ & $0,11^{\mathrm{ns}}$ & $0,21^{\mathrm{ns}}$ & $0,82^{n s}$ & $0,13^{\mathrm{ns}}$ & $0,34^{\mathrm{ns}}$ \\
\hline $\begin{array}{c}\text { EEL x EE x } \\
\text { AE }\end{array}$ & $1,01^{\mathrm{ns}}$ & $1,49^{\text {ns }}$ & $1,03^{\text {ns }}$ & $2,72^{*}$ & $1,65^{\mathrm{ns}}$ & $3,63^{*}$ \\
\hline CV\% & 5,85 & 8,33 & 7,24 & 9,11 & 18,90 & 17,62 \\
\hline
\end{tabular}

Médias seguidas pela mesma letra minúscula, na coluna, não diferem significativamente entre si, ao nível de 5 $\%$ de probabilidade, pelo teste de Tukey. ${ }^{\text {ns }}=$ Não significativo; ${ }^{*}=$ significativo a $5 \%$ de probabilidade, ${ }^{* *}=$ significativo a $1 \%$ de probabilidade. 
TABELA 2 Análises de superfícies de resposta para altura da cabeça no arranjamento triangular (ACT) e quadrangular (ACQ), diâmetro da cabeça no arranjamento triangular (DCT) e quadrangular (DCQ); índice de formato da cabeça no arranjamento triangular (IFCT) e quadrangular (IFCQ); compacidade no arranjamento triangular (CT) e quadrangular (CQ), massa fresca no arranjamento triangular (MFT) e quadrangular (MFQ) e produtividade total estimada no arranjamento triangular (PTET) e quadrangular (PTEQ), obtidas pelo híbrido de repolho 'Astrus Plus', em diferentes densidades de plantio e arranjamentos espaciais.

\begin{tabular}{|c|c|c|c|c|c|c|}
\hline $\begin{array}{c}\text { Parâmetros do } \\
\text { modelo }\end{array}$ & ACT & $A C Q$ & DCT & DCQ & IFCT & IFCQ \\
\hline $\mathrm{b}_{0}$ (Intercepto) & 19,81 & 13,02 & 52,77 & 92,87 & 1,01 & 0,79 \\
\hline$b_{1}(E L)$ & 12,52 & $-97,14$ & 161,13 & $-257,92$ & $-0,49$ & 0,26 \\
\hline$b_{2}(E P)$ & 31,79 & 187,08 & 203,93 & 673,85 & $-0,54$ & $-0,61$ \\
\hline$b_{3}(E L \times E L)$ & $-7,08$ & 94,00 & $-107,25$ & 218,14 & 0,50 & $-0,31$ \\
\hline $\mathrm{b}_{4}(\mathrm{EP} \times \mathrm{EL})$ & 1,46 & 6,46 & 47,66 & $-52,78$ & $-0,35$ & 0,27 \\
\hline \multirow[t]{2}{*}{$b_{5}(E P \times E P$} & $-27,50$ & 180,93 & $-183,47$ & $-587,21$ & 0,79 & 0,44 \\
\hline & CT & $\mathbf{C Q}$ & MFT & MFQ & PTET & PTEQ \\
\hline $\mathrm{b}_{0}$ (Intercepto) & $\begin{array}{c}-0,08 \\
\end{array}$ & 2,20 & \begin{tabular}{|c|}
$-1,31$ \\
\end{tabular} & $-1,89$ & 43,96 & 89,07 \\
\hline$b_{1}(E L)$ & 4,93 & $-3,64$ & 1,07 & 4,07 & $-34,37$ & $-82,76$ \\
\hline$b_{2}(E P)$ & 3,69 & 4,60 & 6,75 & 5,71 & 153,96 & 16,27 \\
\hline$b_{3}(E L \times E L)$ & $-2,62$ & 2,74 & 0,78 & $-1,61$ & 54,42 & 67,72 \\
\hline$b_{4}(E P \times E L)$ & $-2,10$ & 0,67 & $-1,39$ & $-2,25$ & $-131,95$ & $-79,00$ \\
\hline$b_{5}(E P \times E P$ & $--1,50$ & $-3,63$ & $-4,12$ & $-2,73$ & $-108,12$ & $-4,45$ \\
\hline
\end{tabular}

$* *$ significativo a $1 \%$ de probabilidade, ${ }^{\text {ns }}=$ não significativo.

Para a característica altura da cabeça de repolho, tanto os espaçamentos entrelinhas, quanto os espaçamentos entre plantas afetaram de forma significativa a altura das cabeças, sendo que, maiores espaçamentos resultaram em plantas com maiores valores dessa característica. Isto pode ter ocorrido devido ao menor sombreamento entre plantas e a menor competição por água e nutrientes proporcionados nos maiores espaçamentos em relação aos espaçamentos menores. Resultado esse também relatado por SILVA et al. (2011), onde citam que a intensidade da competição intraespecífica estabelecida pelo manejo do espaçamento/densidade populacional causa modificações na planta, que repercutem tanto na produtividade da cultura, quanto na qualidade do repolho colhido e, consequentemente, na rentabilidade do cultivo.

Com relação ao diâmetro de cabeça, foi possível observar menor diâmetro da cabeça $(162,01 \mathrm{~mm})$ quando as plantas foram cultivadas no menor espaçamento $(0,40$ $\mathrm{m}$ entrelinhas $\times 0,30 \mathrm{~m}$ entre plantas), enquanto que o máximo valor de diâmetro da cabeça $(192,87 \mathrm{~mm})$ foi obtido quando o espaçamento foi de $0,8 \mathrm{~m}$ entrelinha e de 0,66 m entre plantas (Figura 1). 


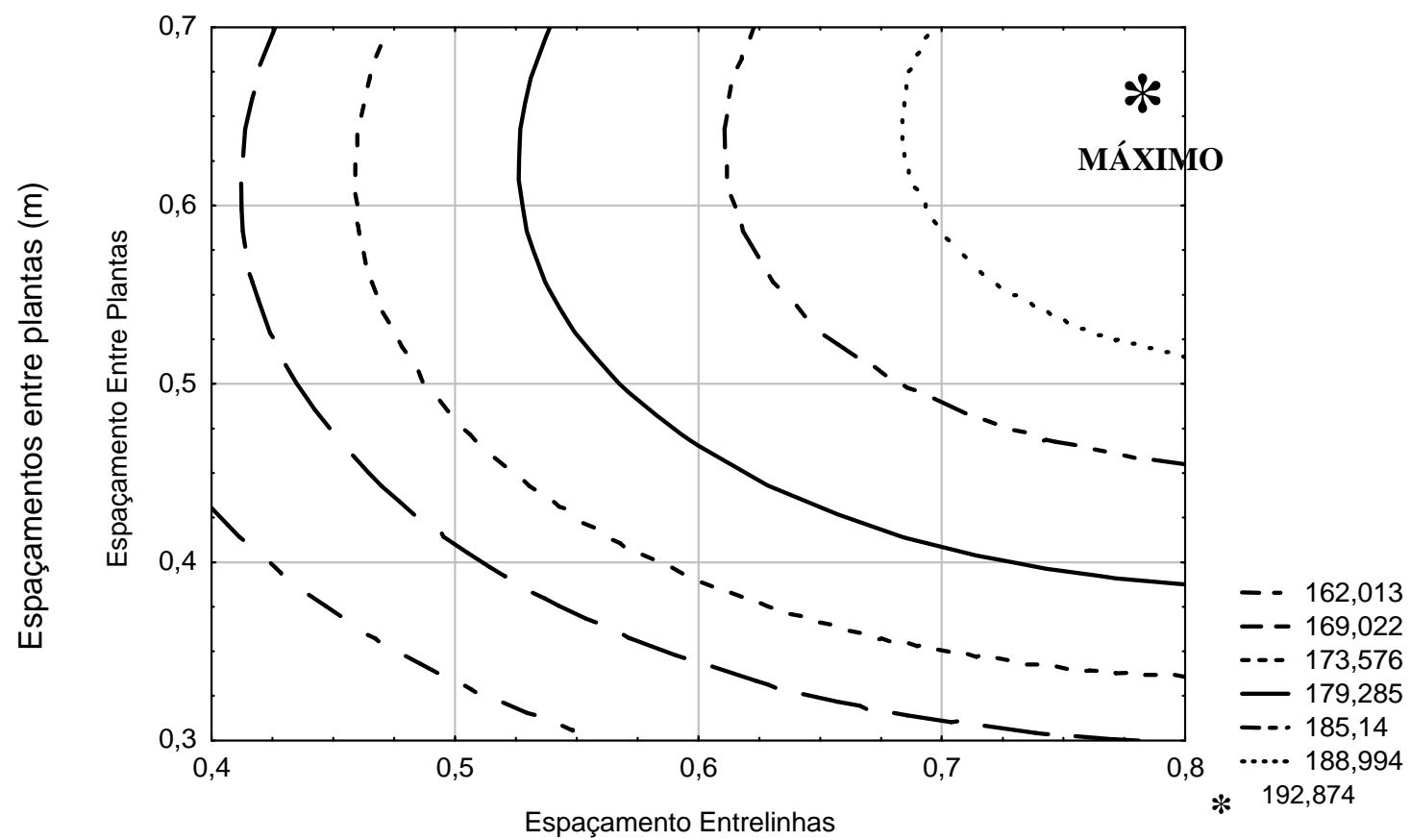

$Z=52,767+161,136 x+203,943 y-107,254 x^{2}+47,656 x y-183,479 y^{2}$

FIGURA 1 Isolinhas da superfície de resposta para diâmetro da cabeça no arranjamento triangular, obtidas pelo híbrido de repolho 'Astrus Plus', em diferentes densidades de plantio.

Segundo PÔRTO et al. (2012), avaliando diferentes densidades e épocas de plantio em couve-flor, a diminuição do diâmetro da cabeça pode ter ocorrido devido a maior competição intraespecífica, o que acarreta menor tamanho no diâmetro do caule e, possivelmente, modificação na translocação de água, nutrientes e fotoassimilados e, consequentemente, redução no tamanho das cabeças. Efeitos semelhantes sobre o diâmetro também foram observados por AQUINO et al. (2005) e SILVA et al. (2011), no entanto, essa redução pode ser atraente se for considerado que cada vez mais o mercado consumidor brasileiro prefere cabeças de repolho de menor tamanho evitando, dessa forma, desperdícios.

Para o índice de formato da cabeça não houve diferença significativa entre os fatores avaliados, portanto, independente do espaçamento entrelinhas, entre plantas e do arranjamento espacial utilizado, as cabeças de repolho tiveram valores de índice de formato semelhantes (Tabela 1).

A característica de compacidade da cabeça não foi influenciada pelos fatores espaçamentos entrelinhas e arranjamentos espaciais, porém foi influenciada significativamente pelo fator espaçamento entre plantas (Tabela 1), sendo que cabeças mais compactas foram obtidas quando cultivadas no espaçamento entre plantas de 0,7 $\mathrm{m}(2,82)$, e $0,5 \mathrm{~m}(2,69)$. Essa mensuração é de extrema importância, já que cabeças mais compactas resistem mais ao transporte e podem ter maior conservação póscolheita. 
Sobre a massa fresca da cabeça foi possível observar que houve influência significativamente dos fatores isolados (espaçamento entre plantas e entre linhas), com exceção do fator arranjamentos espaciais. Analisando as isolinhas da superfície de resposta para massa fresca no arranjamento triangular (Figura 2), verifica-se que, com o aumento do espaçamento entrelinhas e entre plantas ocorreu o aumento da massa fresca, sendo que o maior valor $(1,968 \mathrm{~kg})$, foi obtido no espaçamento de 0,8 x 0,68 m (Figura 2). O mesmo foi observado por SILVA (2009), que estudou o crescimento e produtividade de repolho roxo em função de espaçamentos entrelinhas e entre plantas.

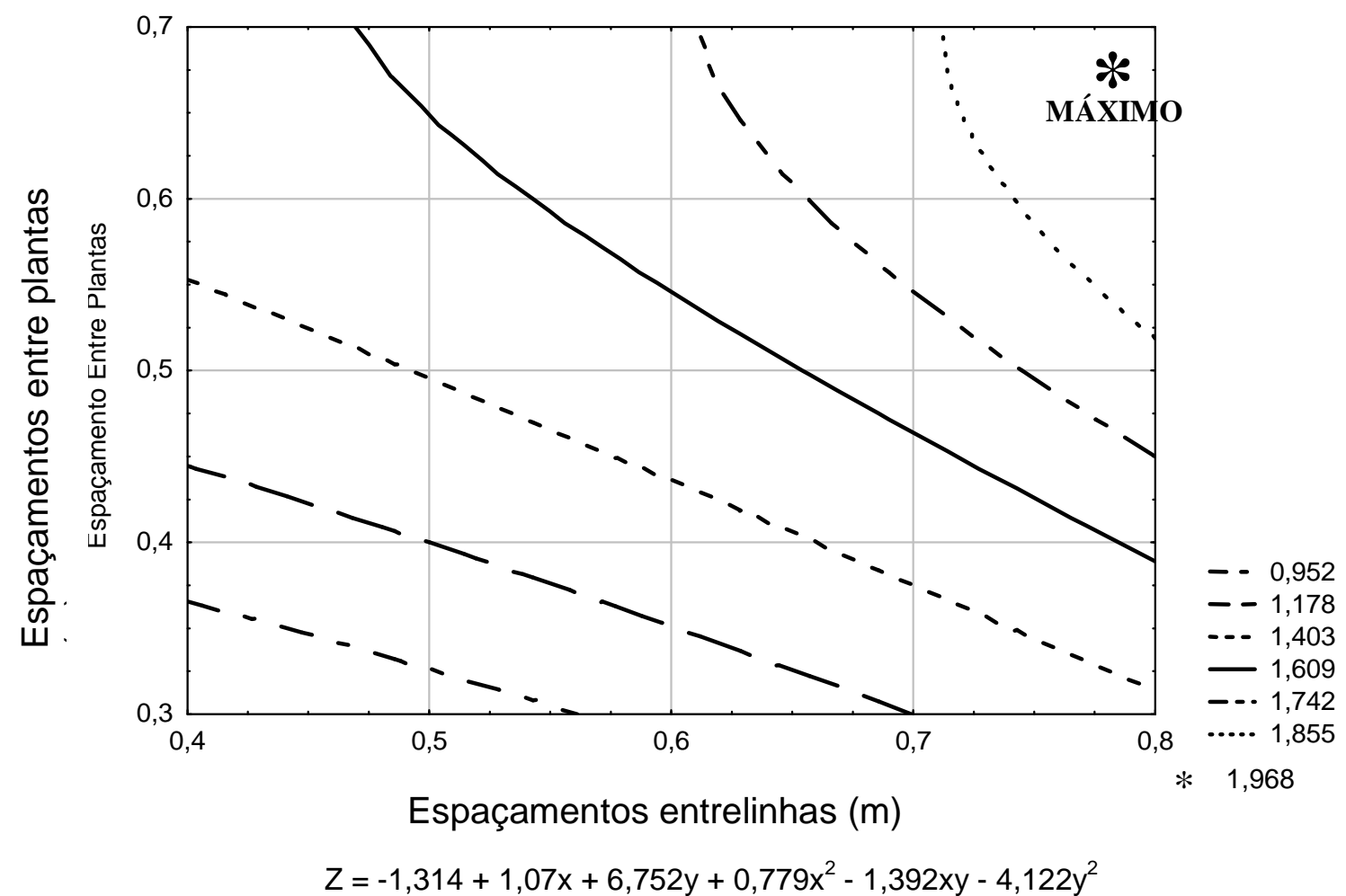

FIGURA 2 Isolinhas da superfície de resposta para massa fresca no arranjamento triangular, obtidas pelo híbrido de repolho 'Astrus Plus', em diferentes densidades de plantio.

De acordo com AQUINO et al. (2005) a redução da massa fresca média de cabeça no menor espaçamento, sem diminuição da produção de massa fresca de cabeça por área, é interessante ao produtor de repolho, pois permite obter cabeças com tamanho dentro dos padrões comerciais exigidos pelo mercado consumidor (cabeças com 1,0 a 1,5 kg de massa fresca), mantendo a produtividade por área, facilitando a comercialização e o escoamento da produção e alcançando melhores preços, sobretudo em períodos em que há maior oferta do produto.

Resultados semelhantes também foram relatados por ŽNIDARČIČ et al. (2007), e SILVA et al. (2011) em repolho, corroborando com CASTRO et al. (1987), quando afirmam que a redução do espaçamento entre plantas conduz à maior competição pelos fatores de crescimento, fazendo com que estas permaneçam menores, associado ao menor espaço físico disponível limitando a expansão foliar.

ENCICLOPÉDIA BIOSFERA, Centro Científico Conhecer - Goiânia, v.11 n.22; p.3578 2015 
Para a produtividade total estimada (Tabela 1), observa-se que 0 menor espaçamento entrelinhas apresentou maior produtividade $\left(58,75 \mathrm{t} \mathrm{ha}^{-1}\right)$, diferindo estatisticamente dos demais. Isto pode ser explicado pelo fato de que quanto mais adensado for o cultivo, maior será o número de plantas por hectare e, consequentemente, maior será a produtividade. Porém, não se deve esquecer que a qualidade do produto também deve ser mantida.

Comportamentos similares também foram averiguados por BORA et al. (1992), ao notarem que o menor espaçamento entre plantas também apresentou maior produtividade $\left(56,47 \mathrm{t} \mathrm{ha}^{-1}\right)$, não diferindo estatisticamente das plantas espaçadas de $0,5 \mathrm{~m}\left(51,83 \mathrm{t} \mathrm{ha}^{-1}\right)$. Este mesmo comportamento foi observado para outras culturas, onde a redução no espaçamento apesar de proporcionar diminuição na massa média de plantas pode, até certo limite, aumentar a produção por área (SILVA et al., 2000; FERREIRA et al., 2002, PÔRTO et al., 2012).

SILVA et al. (2011) trabalhando com diferentes densidades em repolho roxo, ainda ressaltam um efeito de compensação, pois a medida que aumenta-se a população, a produtividade cresce, pois há uma compensação da menor massa da "cabeça" pelo aumento do número de plantas na área.

\section{CONCLUSÃO}

Considerando a atual preferência brasileira e a busca de elevadas produtividades pelo produtor, o espaçamento de $0,4 \times 0,5 \mathrm{~m}$ (entrelinhas e entre plantas, respectivamente) seria o mais indicado, por promover cabeças com características comercializáveis, mantendo alta produtividade. Quanto ao arranjamento espacial (triangular ou quadrangular), não houve interferência nas características avaliadas.

\section{REFERÊNCIAS \\ AGRIANUAL. Anuário da Agricultura Brasileira. São Paulo: Argos Comunicações, 2015. $354 \mathrm{p}$.}

AQUINO, L. A.; PUIATTI, M.; PEREIRA, P. R. G.; PEREIRA, F. H. F.; LADEIRA, I. R.; CASTRO, M. R. S. Efeito de espaçamento e doses de nitrogênio sobre as características qualitativas na produção do repolho. Horticultura Brasileira, Brasília, v.23, n. 1, p. 100-104, 2005.

BARBOSA, J. C.; MALDONADO, W. AgroEstat - sistema para análises estatísticas de ensaios agronômicos versão 1.1.0.694. Jaboticabal: FCAV/UNESP, 2011.

BORA, G. C.; DEKA, B. C.; SHADEQUE, A. Effect of different levels of nitrogen and spacing on head yield of cabbage (Brassica oleraceae convar capitata var capitata). Indian Journal of Agricultural Sciences, v. 62, p. 527-528, 1992.

CASTRO, P.R.C.; FERREIRA, S.O.; YAMADA, T. Ecofisiologia da produção agrícola. Piracicaba: Associação Brasileira para Pesquisa da Potassa e do Fosfato, 1987. 249p.

EMBRAPA. Centro Nacional de Pesquisa de Solos. Sistema Brasileiro de Classificação do solo. 3. ed. Rio de janeiro: Embrapa, 2014. 
FERREIRA, W. R.; RANAL, M. A.; FILGUEIRA, F. A. R. Fertilizantes e espaçamento entre plantas na produtividade da couve-da-Malásia. Horticultura Brasileira, v. 20, n. 4, p. 635-640, 2002.

FILGUEIRA, F. A. R. Novo Manual de olericultura: agrotecnologia moderna na produção e comercialização de hortaliças. 3. ed. Viçosa-MG: UFV, 2012. p. 267-285, 2012.

KRANZ, W. M. População de plantas - feijão no Paraná. Londrina: Fundação Instituto Agronômico do Paraná. p. 115-125. (Circular, 63).1989.

LÉDO, F. J. S.; SOUZA, J. A.; SILVA, M. R. Avaliação de cultivares e híbridos de repolho no Estado do Acre. Horticultura Brasileira, v. 19, n. 2, p. 138-140, 2000.

PÔRTO, D. R. Q.; CECILIO FILHO, A. B.; REZENDE, B. L. A.; BARROS JUNIOR, A. P.; SILVA, G. S. Densidade populacional e época de plantio no crescimento e produtividade da couve-flor cv. Verona 284. Revista Caatinga, v. 25, n. 2, p. 92-98, 2012.

SEMINIS. Astrus Plus. Disponível em: <http://www.seminis.com.br/products/repolho/astrus_plus.asp> Acesso em: 10 jun. 2011.

SILVA JUNIOR, A. A. Adubação mineral e orgânica em repolhos. II. Concentração de nutrientes na folha e precocidade. Horticultura Brasileira, v. 5, n. 1, p. 15-17, 1987.

SILVA, G. S. Crescimento e produtividade de repolho roxo em função de espaçamentos entre linhas e entre plantas. 2009. 46 f. Dissertação (Mestrado em Agronomia) - Universidade Estadual Paulista, Faculdade de Ciências Agrárias e Veterinárias, Jaboticabal, 2009.

SILVA, G. S.; CECILIO FILHO, A. B.; BARBOSA, J. C.; ALVES, A. U. Espaçamentos entrelinhas e entre plantas no crescimento e na produção de repolho roxo. Bragantia, v. 70, n. 3, p.538-543, 2011.

SILVA, V. F.; NETO, F.; NEGREIROS, M. Z.; PEDROSA, J. F. Comportamento de cultivares de alface em diferentes espaçamentos sob temperatura e luminosidade elevadas. Horticultura Brasileira, v. 18: 183-187, 2000.

THOMÉ, V. M. R. Crescimento, desenvolvimento e rendimento de grãos de um cultivar de feijoeiro de hábito de crescimento arbustivo determinado, em função de época de semeadura, espaçamento entre linhas e densidade de plantas. 1985. 139 f. Dissertação (Mestrado em Agronomia) - Faculdade de Agronomia, Porto Alegre, 1985. 
TRANI, P. E.; PASSOS, F. A.; AZEVEDO, J. A.; TAVARES, M. Brócolos, couve-flor e repolho. In: RAIJ, B. Van.; CANTARELLA, H.; QUAGGIO, J. A.; FURLANI, A. M. C. (Ed.). Recomendações da adubação e calagem para o Estado de São Paulo. 2. ed. Campinas: IAC, (Boletim Técnico, 100), 1997, 285 p.

WOOLLEY, J.; DAVIS, J. H. C. The agronomy of intercropping with beans. In: SCHOONHOVEN AV; VOYSEST O (Ed.). Common beans: Research for crop improvement. Wiltshire, UK: Redwood Press, p. 707-735.1991.

ŽNIDARČIČ, D.; KACJAN-MARŠIĆ, N.; OSVALD, J.; POŽRL, T.; TRDAN, S. Yield and quality of early cabbage in response to within-row plant spacing. Acta Agriculturae Slovenica, v.89, p.15-23, 2007. 